\title{
Assessment of Characteristics, Sources, and Anxiety Levels in Women with Single Parent Status during the COVID-19 Pandemic
}

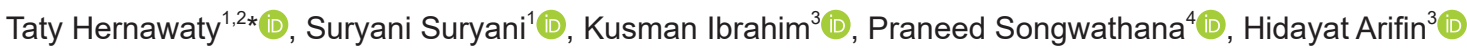 \\ ${ }^{1}$ Department of Mental Health Nursing, Faculty of Nursing, Universitas Padjadjaran, Bandung, Indonesia; ${ }^{2}$ Doctoral Study \\ Program, Faculty of Medicine, Universitas Padjadjaran, Bandung, Indonesia; ${ }^{3}$ Department of Medical Surgical Nursing, \\ Faculty of Nursing Universitas Padjadjaran, Bandung, Indonesia; ${ }^{4}$ Department of Medical Surgical Nursing, Prince of Songkla \\ University, Hat Yai, Songkhla, Thailand
}

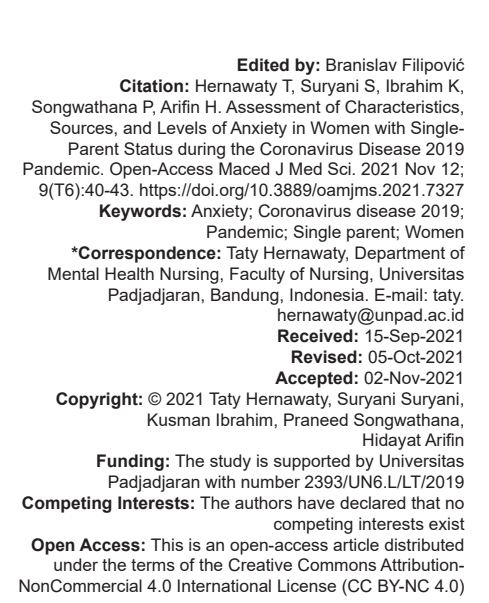

\begin{abstract}
BACKGROUND: The coronavirus disease 2019 (COVID-19) pandemic had an impact on people globally, including mothers living in coastal regions. Therefore, this study aims at identifying the psychological status of single mothers living in the coastal regions of Indonesia.

METHODS: A descriptive quantitative cross-sectional design was used with non-probability sampling in coastal regions of West Java, Indonesia. Furthermore, the Zung Self Rating Anxiety Scale was used to assess the anxiety level of single mothers.

RESULTS: The anxiety of single mothers during the COVID-19 pandemic was generally moderate $(n=45.77 .59 \%)$ with $44.83 \%$ attributing it to health and the economy. Furthermore, previous results showed that this condition was observed in the elderly $(n=38.65 .52 \%)$, though it lasted $<5$ years in the majority of cases $(n=33.56 .90 \%)$ Symptoms associated with the anxiety of single mothers during the pandemic include an increase in restlessness nervousness, and anxiety.

CONCLUSION: The economy and health of single mothers were the primary sources of anxiety during the COVID19 pandemic. A high percentage of these women suffer from mild anxiety and require immediate care to prevent the development of other health problems. Therefore, health cadres and community nurses are expected to take action to achieve optimal psychological welfare among single mothers during the pandemic. Further study can be conducted by focusing on the theme of defense mechanisms or resilience.
\end{abstract}

\section{Introduction}

The coronavirus disease 2019 (COVID-19) has become a global pandemic affecting a minimum of 25 countries as of June 2, 2020 [1]. Currently, the cumulative number of cases and death toll reported is approximately 197 and 4.2 million, respectively [2]. In Indonesia, 4,133,433 positive COVID-19 cases had been confirmed, with 136,473 deaths, as of September 6, 2021. Meanwhile, the second largest province of West Java had 694,714 confirmed cases, with 13,836 deaths [3].

This virus has an easy mode of transmission, hence standardized masks and physical distancing from people during activities are essential for safety [4]. Furthermore, the COVID-19 pandemic has resulted in the issuance of regulations for millions of individuals, including restrictions on individual movement, closure of non-essential shopping locations, general or special quarantines, and isolation, especially for vulnerable people. The enactment of these rules in addition to having a positive impact in reducing counterproductive work behaviors creates other problems for individuals [2]. Specifically, a study showed that the pandemic caused a decline in psychological well-being and hindered the use of information technology, resulting in a reduced quality of work-life [5]. A similar report showed the prevalence of psychological stress among a community during the COVID-19 pandemic ( $n=514 ; 48.6 \%)$, with a higher number of cases in women [6]. Furthermore, in other studies examining the impact of various regulations during a pandemic, feelings of selfishness, shame, and fear were observed among women living alone [7].

In Indonesia, $15.46 \%$ of women play the role of the family head, with $67.36 \%$ having experienced the death of their spouses. Furthermore, in contrast to the previous 2 years, this figure has increased, with a higher prevalence in rural areas [8]. This situation is similar to a study exploring the characteristics of single-parent families in Greece, where $87.7 \%$ of the 206 participants were women, mainly due to divorce [9]. Furthermore, $14.56 \%$ of these individuals were identified as family heads in Indonesia's second-largest province, West Java [8]. 
Several variables indicate single mothers face difficult life situations, with a study showing that a majority encountered moderate adjustment problems and were primarily maladjusted [10]. Futhermore, other reports illustrate the presence of stigma among single mothers. A study conducted by DeJean et al. on 1,351 subjects, explored the differences in attitudes towards single parents. According to the results, single mothers were perceived to have inferior personal characteristics and child-rearing abilities in comparison to fathers [11].

In Indonesia, $69.43 \%$ of single mothers have informal jobs or work as laborers or employees [8]. These women play multiple roles, including caring for their children and household, as well as working to cover their necessities. Making a living in coastal regions is extremely dependent on the conditions of the coastal and ocean resources. The restrictions imposed during the pandemic also had a significant impact on the economic activities of these communities. Therefore, this study aims to determine the characteristics, sources, and anxiety levels of women with singleparent status in coastal areas during the COVID-19 pandemic.

\section{Methods}

\section{Research design, participants, and measurements}

A cross-sectional design was used to conduct this study in the coastal regions of West Java, Indonesia. The subjects included 58 single mothers, who were recruited using non-probability sampling.

The questionnaire was distributed via a google form and contained five items measuring demographic characteristics, one open-ended question about the source of anxiety, and 20 items measuring anxiety levels. An explanation and a link regarding the questionnaire as well as a willingness to participate form were sent to the participants. Furthermore, individuals who did not have or were unable to use the internet were included in the study and assisted by enumerators.

Face validity was conducted on a questionnaire concerning the source of anxiety. The Zung Self Rating Anxiety Scale (SAS/ZRAS) was also used to measure the subject's level of anxiety, with answer choices, including (1) never, (2) sometimes, (3) some of the time, and (4) almost every time. The SAS/ZRAS instrument is a valid tool with the lowest and highest values of 0.663 and 0.918 , as well as with a 0.965 rating. Therefore, the $r$ count is greater than the $r$ table, with a significance level of $5 \%$.

\section{Data analysis}

A descriptive statistics, with a one-way analysis, was performed and the SAS/ZRAS instrument was used to assess the subject's level of anxiety. In addition, an independent sample t-test and bivariate Pearson correlation were used to analyze the data. The subject characteristics included age group, educational background, length of time without a partner, occupation, number of family members, and sources of anxiety. Subsequently, logistic regression was employed in the determination of anxiety state while the statistical analysis was performed using IBM-SPSS version 20 software.

\section{Ethical considerations}

The protocol applied in this study was reviewed and approved by the Health Research Ethics Committee of Padjadjaran University (Surat No. 456/UN.6.KEP/ $E C / 2021)$. Furthermore, the Head of the National Unity and Political Agency of West Java Province (Letter No.070/0078/SKP/I//2021) provided the permit for data collection. The subjects were also given written and informed consent.

\section{Results}

\section{of anxiety}

\section{Demographic characteristics and sources}

Table 1 shows that 58 subjects had an average age of 50.24 years (SD 14.19), with predominantly elementary school education background $(n=50,86.21 \%)$. The majority of participants lost their partners after an average of 7.65 years (SD 5.41) and had informal jobs $(n=58,100)$. Furthermore, $35(60.34 \%)$ had more than two family members, while the others ( $n=23,39.66 \%$ ) had less than two. Approximately half of the subjects ( $n=26,44.8 \%)$ perceived that their health and economy were sources of anxiety.

\section{Psychological subjects during the COVID-19 pandemic}

Table 2 shows that $45 \quad(77.59 \%)$ and $13(22.41 \%)$ single mothers experienced mild and moderate anxiety during the pandemic. Furthermore, $15(25.86 \%)$ participants complained of frequent dizziness while $17(29.31 \%)$ were more restless, nervous, and anxious than normal. Headaches, neck or muscle pain, and stiffness ( $n=12,20.69 \%$ ) were also frequently experienced. In addition, stiffness, numbness, and tingling in the fingers were reported by the same percentage of participants while $9(15.58 \%)$ felt weak and quickly exhausted. Figure 1 displays the 
Table 1: Demographic characteristics and sources of participants' anxiety $(n=58)$

\begin{tabular}{lc}
\hline Characteristics & $\mathrm{n}(\%)$ \\
\hline Age (years) & \\
$\quad$ Mean (SD) & $50.24(14.19)$ \\
Educational background & $50(86.21)$ \\
$\quad$ Primary school & $3(5.17)$ \\
$\quad$ Junior high school & $5(8.62)$ \\
$\quad$ Senior high school & \\
Long time alone (year) & $7.65(5.41)$ \\
$\quad$ Mean (SD) & \\
Job-status & $58(100)$ \\
$\quad$ Informal & \\
Members of the family & $23(39.66)$ \\
$\quad$ <2 people & \\
Source of anxiety & $9(15.5)$ \\
$\quad$ Health+Economy+Education & $26(44.8)$ \\
Health+Economy & $3(5.2)$ \\
Health+Education & $7(12.07)$ \\
$\quad$ Health & $13(22.41)$ \\
$\quad$ Economy & \\
\hline SD: Standard deviations. &
\end{tabular}

percentage of individuals that experienced an increase in the rate and contraction of their heartbeat.

The relationship between anxiety levels and the characteristics as well as sources of the subject's anxiety during the pandemic

Figure 2 shows that of the 58 subjects, $45(77.59 \%)$ and $13(22.41 \%)$ experienced mild and moderate anxiety, respectively.

Table 2: Anxiety according to the characteristics of the subject $(n=58)$

\begin{tabular}{|c|c|c|c|}
\hline \multirow[t]{2}{*}{ Variable } & \multicolumn{3}{|l|}{$\begin{array}{l}\text { Anxiety } \\
\mathrm{n}(\%)\end{array}$} \\
\hline & $\begin{array}{l}\text { Mild } \\
\mathrm{n}(\%)\end{array}$ & $\begin{array}{l}\text { Moderate } \\
\mathrm{n}(\%)\end{array}$ & $\begin{array}{l}\text { Overall } \\
\mathrm{n}(\%)\end{array}$ \\
\hline \multicolumn{4}{|l|}{ Age } \\
\hline Teenager & $4(5.09)$ & $1(1.72)$ & $5(8.62)$ \\
\hline Adult & $6(10.34)$ & $5(8.62)$ & $11(18.97)$ \\
\hline Elderly & $32(55.17)$ & $6(10.34)$ & $38(65.52)$ \\
\hline Older & $3(5.17)$ & $1(1.72)$ & $7(12.07)$ \\
\hline \multicolumn{4}{|l|}{ Education } \\
\hline Primary school & $35(60.34)$ & $4(6.90)$ & $39(67.24)$ \\
\hline Junior high school & $6(10.34)$ & $7(12.07)$ & $13(22.41)$ \\
\hline Senior high school & $4(6.90)$ & $2(3.45)$ & $2(3.45)$ \\
\hline \multicolumn{4}{|l|}{ Long time alone (year) } \\
\hline $1.5-5$ & $16(27.59)$ & $9(15.52)$ & $25(43.10)$ \\
\hline$>5$ & $29(50.60)$ & $4(6.90)$ & $33(56.90)$ \\
\hline \multicolumn{4}{|l|}{ Job status } \\
\hline Informal & $37(63.79)$ & $21(36.21)$ & $58(100)$ \\
\hline Formal & $0(0.0)$ & $0(0.0)$ & $0(0.0)$ \\
\hline \multicolumn{4}{|l|}{ Members of the family (people) } \\
\hline $1-2$ & $17(29.31)$ & $3(5.17)$ & $20(34.48)$ \\
\hline$>2$ & $28(48.28)$ & $10(17.24)$ & $38(65.52)$ \\
\hline \multicolumn{4}{|l|}{ Source of anxiety } \\
\hline Health+Economy+Education & $6(10.34)$ & $3(5.17)$ & $9(69.2)$ \\
\hline Health+Economy & $23(39.66)$ & $3(5.17)$ & $26(44.83)$ \\
\hline Health+Education & $3(5.17)$ & $0(0.00)$ & $3(5.17)$ \\
\hline Health & $6(10.34)$ & $1(1.72)$ & $7(12.07)$ \\
\hline Economy & $7(12.07)$ & $6(10.34)$ & $13(22.41)$ \\
\hline
\end{tabular}

\section{Discussion}

According to the results of this study conducted on 933 individuals by the Centers for Disease Control and Prevention in August 2020, over 65 subjects experienced several forms of anxiety. In addition, the mental health of other age groups was more affected by the pandemic than the elderly [12]. A qualitative study on several participants aged 55-65 also illustrated that

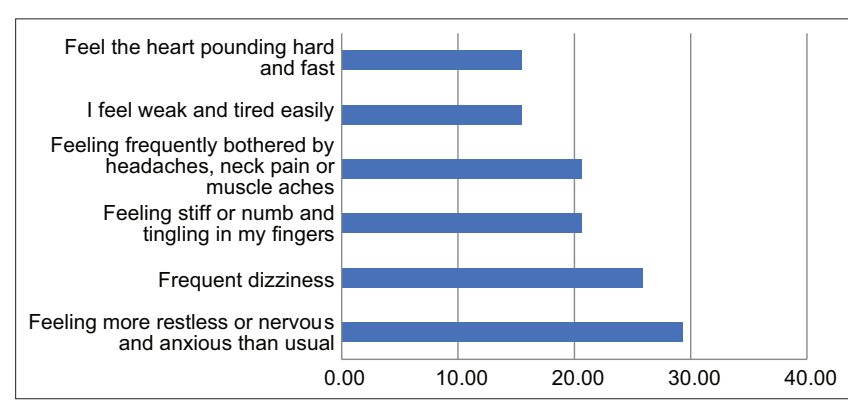

Figure 1: Proportion of anxiety symptoms in single mothers during the coronavirus disease 2019 pandemic

although subjects experienced anxiety, they were still able to execute their daily activities [13]. During this pandemic, single mothers and the elderly were also able to perform their daily activities as though they had no psychological problems.

Furthermore, over half of the subjects $(56.90 \%)$ experienced separation from their partner for more than 5 years. According to research results, this sense of loss decreases over time, usually after 18 months [14]. Although these subjects had been without partners for more than 5 years $(n=33,56.90 \%)$, half of them $(50.60 \%)$ experienced only mild anxiety.

The most prevalent complaints experienced by participants in this study include feelings of restlessness/ nervousness, anxiety, and dizziness. Furthermore, mild anxiety should be treated, even though this condition is tolerable because previous reports show that ignoring these symptoms can lead to the development of other diseases [14].

This study results also demonstrate that $60.34 \%$ of participants have more than two family members, which might serve as a support system. In addition, this finding was obtained from a review of family support in patients who exhibited a perceived benefit compared to those without assistance. Although this study was aimed at stroke patients, the emotional states described in these individuals had little in common with women, who had lost a partner. Also, other studies reported that anxious people are more likely to have low-income families and poor quality of life [15].

The limitations of this study include (1) mobility restrictions during the pandemic, which required the researchers to conduct most of the data collection via mobile phones, (2) biased data because some of the subjects did not have a smartphone or understand how to use it, and (3) restriction to one coastal area, hence the study cannot be generalized to the entire population of single mothers in the country.

\section{Implications for public health}

This study highlights the anxiety level of single mothers during the COVID-19 pandemic. Although a majority of these individuals experience mild levels of anxiety, a few have certain complaints, with the potential 
to trigger other health problems. Therefore, community nurses are expected to take preventive measures, to achieve optimal psychological welfare in single mothers during the pandemic.

Furthermore, the results indicated that health and economic factors were the sources of anxiety among single mothers living in coastal areas during the COVID-19 pandemic. Therefore, community nurses, health cadres, and local governments are required to care for the coastal community culture. Furthermore, nurses are expected to develop skills on how to provide multicultural care [16], [17].

\section{Conclusion}

The results highlight the anxiety levels of single mothers during the COVID-19 pandemic. A majority of the participants experienced mild levels of anxiety, with frequent physical complaints, such as feelings of restlessness, nervousness, anxiety, and dizziness. In addition, health and economic factors were the primary sources of anxiety among these women living in coastal areas. Therefore, health cadres and community nurses are expected to take action to achieve optimal psychological welfare in single mothers during the pandemic. Further research can be conducted by focusing on the theme of defense mechanisms or resilience.

\section{Acknowledgments}

The authors are grateful to the Padjadjaran University for their kind support. The authors are also grateful to the Head of the National and Political Unity Agency of West Java Province for their permission and cooperation while conducting this study, as well as the subjects' time and information provided.

\section{References}

1. Wu YC, Chen CS, Chan YJ. The outbreak of COVID-19: An overview. J Chin Med Assoc. 2020;83(3):217-20. https://doi.

Author Queries???

AQ2: Kindly provide image and caption for Figure 2

AQ3: Kindly provide last accessed details

\section{org/10.1097/JCMA.0000000000000270}

PMid:32134861

2. Nemteanu MS, Dabija DC. The influence of internal marketing and job satisfaction on task performance and counterproductive work behavior in an emerging market during the covid-19 pandemic. Int J Environ Res Public Health. 2021;18(7):3670. https://doi.org/10.3390/ijerph18073670

PMid:33915926

3. Satuan Tugas Penanganan COVID-19. (2021). Peta Sebaran COVID-19. Available from: https://www.covid19.go.id/ peta-sebaran-covid19

4. Mediawati AS, Susanto R, Nurahmah E. The routes of covid-19 transmission: A literature review. J Crit Rev. 2020;7(3):722-3.

5. Susilaningsih FS, Komariah M, Mediawati AS, Lumbantobing VB. Quality of work-life among lecturers during online learning in COVID-19 pandemic period: A scoping review. Malaysian J Med Health Sci. 2021;17:4.

6. Almanasef M, Almaghaslah D. Assessment of psychological distress among the general public in Saudi Arabia during the coronavirus disease-19 pandemic. Open Access Maced J Med Sci. 2021;9:608-13.

7. Giles AR, Oncescu J. Single women's leisure during the coronavirus pandemic. Leisure Sci. 2021;43(2):204-10.

8. Badan Pusat Statistik. Profil Perempuan Indonesia Tahun 2020; 2021. Available from: https://www.kemenpppa.go.id/index.php/ page/read/26/3057/profil-perempuan-indonesia-tahun-2020

9. Antonopoulou DF. The characteristics of single-parent families in Greece. Health Sci J. 2014;8:65.

10. Naz I, Fatima K, Anjum R. Prevalence and correlates of adjustment disorder in single parent mothers. Pak Armed. 2020;7:5.

11. DeJean S, McGeorge C, Carlson T. Attitudes toward nevermarried single mothers and fathers: Does gender matter? J Feminist Fam Ther. 2012;24(2):121-38.

12. Vahia IV, Jeste DV, Reynolds CF. Older adults and the mental health effects of COVID-19. JAMA. 2020;324(22):2253-4. PMid:33216114

13. Sulistiyaningsih R, Rasyid AS, Amalia DN, Harna FF, Mubarok AS. The Anxiety Dynamics Amongst the Elderly During the Covid-19 Pandemic. Ottawa, Canada: Presented at the ICoPsy International Conference of Psychology; 2020.

14. Utz RL, Caserta M, Lund D. Grief, depressive symptoms, and physical health among recently bereaved spouses. Gerontologist. 2012;52(4):460-71. https://doi.org/10.1093/geront/gnr110 PMid:22156713

15. Wang J, Chen $Y$, Tan $C$, Zhao $X$. Family functioning, social support, and quality of life for patients with anxiety disorder. Int J Soc Psychiatry. 2016;62(1):5-11. https://doi. org/10.1177/0020764015584649 PMid:25964447

16. Songwathana P, Chunuan S, Balthip K, Purinthrapibal S, Hui T, Ibrahim $\mathrm{K}$, et al. Cultural competence perspectives from nurses in four Asian countries: A qualitative descriptive study. J Health Sci Med Res. 2021;39(1):57-66.

17. Kusnanto K, Rohmah FA, Wahyudi AS, Arifin H. Mental workload and stress with blood glucose level: A correlational study among lecturers who are structural officers at the university. Syst Rev Pharm. 2020;11(7):253-7. 